\title{
إدخال الحاسب في مناهج المرحلة المتوسطة
}

\section{منصور بن زيل بن إبراهيم الختّلان}

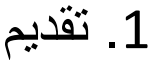

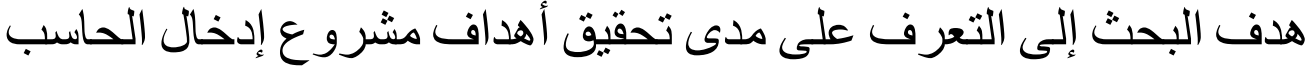

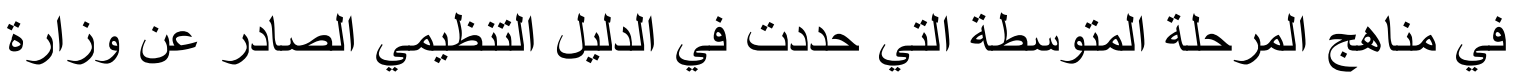

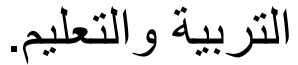

وتعود أهمية البحث إلى تتاوله مجالاً على مستوى من الأهمية ألا وهو

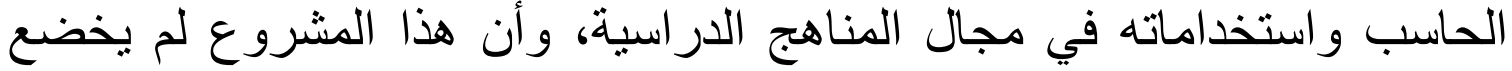

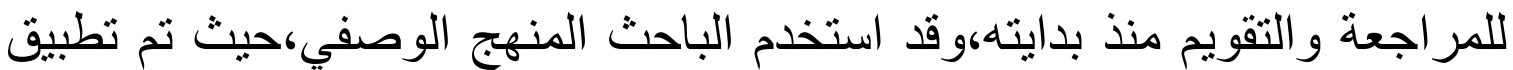
الاستفتاء عل عينة البحث التي شملت (550)معلماً و(29) مدير مدرسة و (12) مشرفاً تربوياً،و أثنارت النتائج التي حصل عليها الباحث إلى تحقيق الأهداف

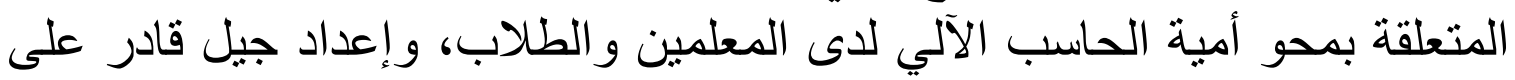

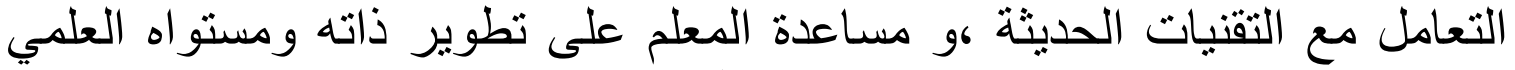

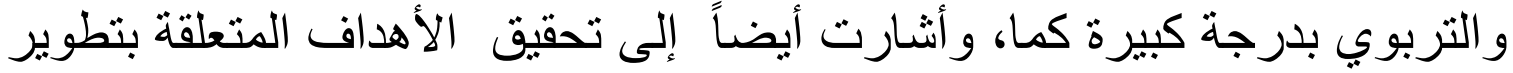
أساليب التدريس باستخدام الحاسب الآلي، و إتاحة الفرصة للطبالئالب للتعلم بطرق

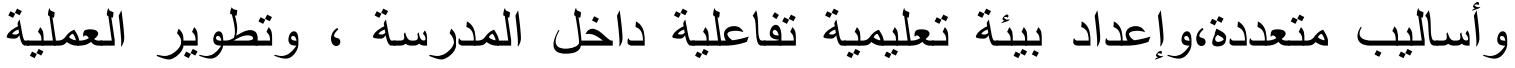

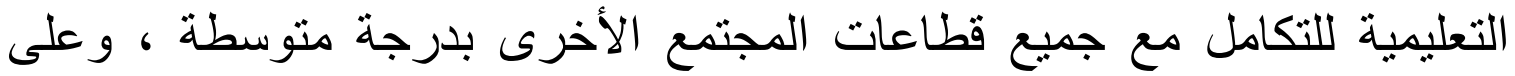

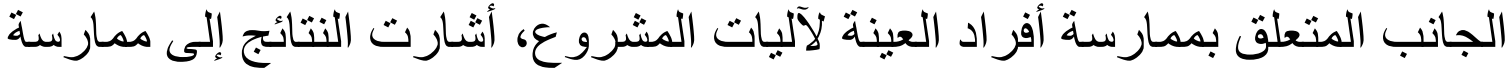

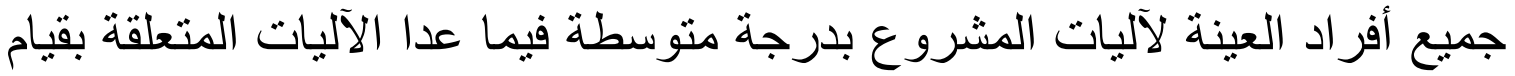
المدرسة بإعطاء المعلمين فكرة واضحة عن المشروع وعقد اجتماعات لإنهات للعاملين

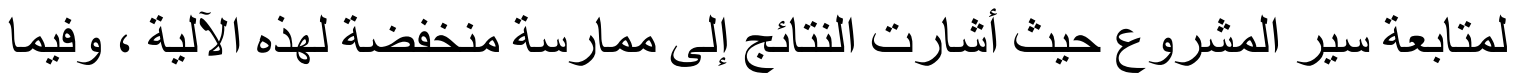

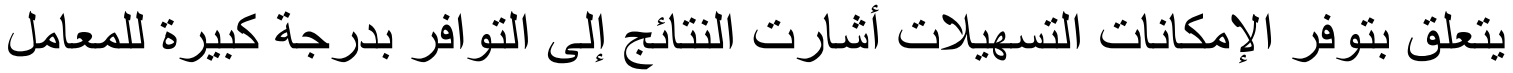

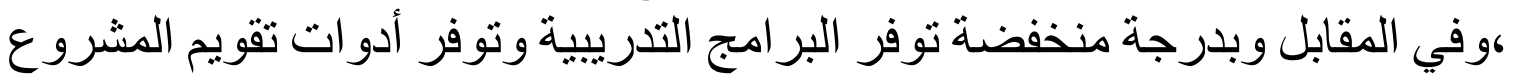

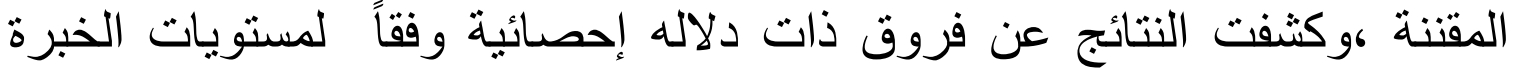

https://ijicet.journals.ekb.eg/ IJAI المجلة الدولية للأكاء الإصطناعى فى التعليم والتدريب 
و المستوى التعليمي لأفراد العينة والتأهيل التربوي ، إما المعوقات فقد جاءت

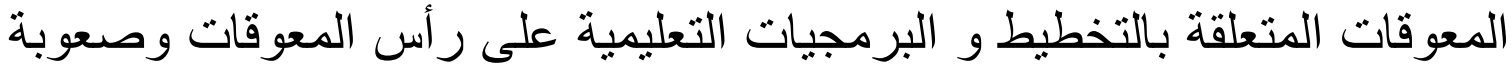

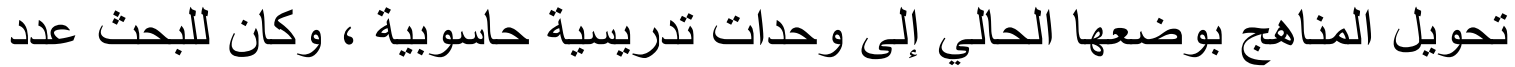

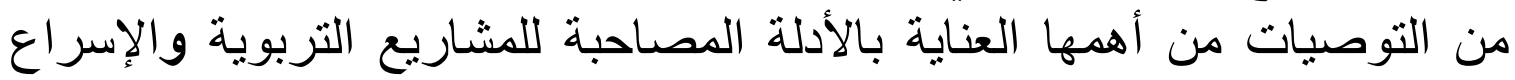

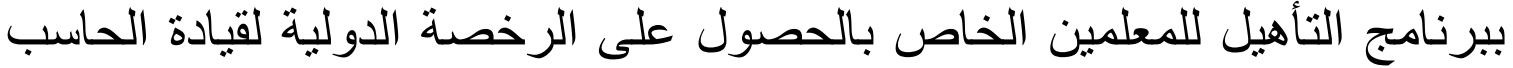
ICD1

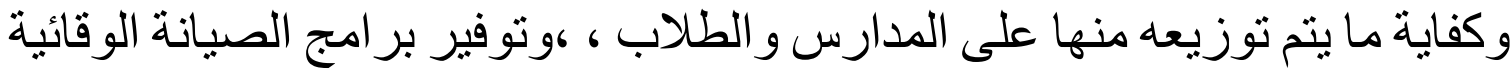

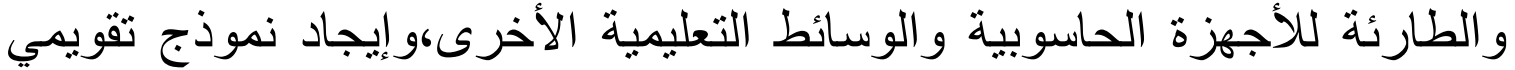

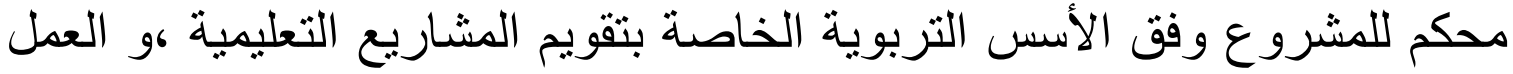

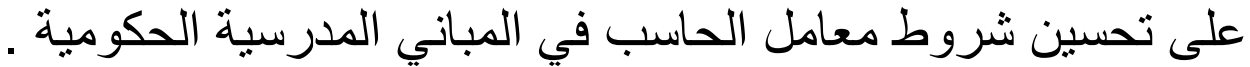

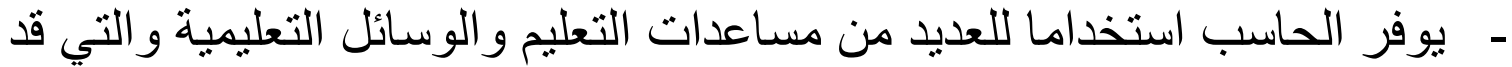
لا تتو افر لدى العديد من المتعلمين من الوسائل السمعية و البصرية التقليدية.

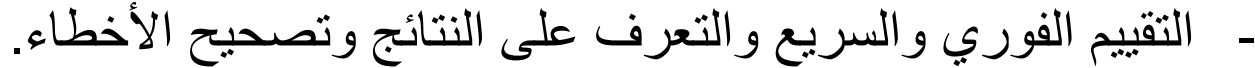
- - مر اعاة الفروق الفردية لكل متعلم نتيجة لتحقيق الذاتية في الاستخدام.

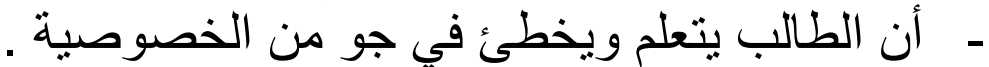
- - يمكن الطالب تخطي بعض المر احل التي ير اها سهلة أو غير فئ مناسبة . - - المرونة حيث يسهل تعديل وتحديث المحتوى التعليمي أو التدريبي .

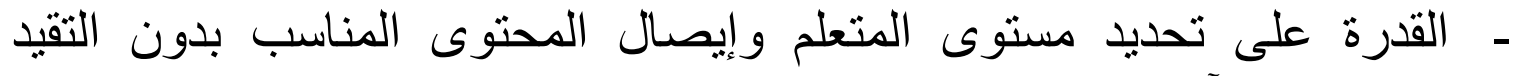
بالمتعلمين الآخرين - - سهولة التعرف على المر احل السابقة التي اجناز ها المتعلم .

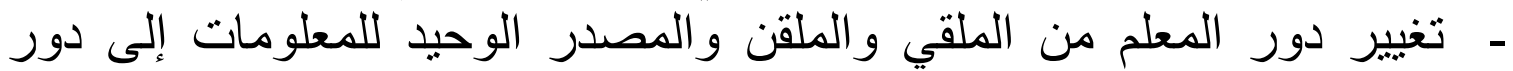
الموجه و المشرفيز دورن. و إدر الك لأهمية تطبيقات التعليم الإلكتروني أقرت وز وزارة التربية والتعليم

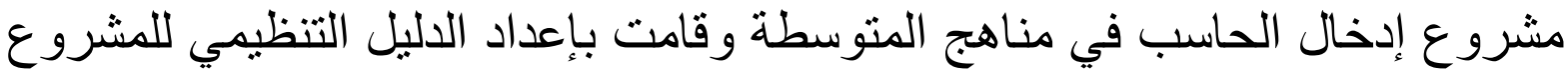

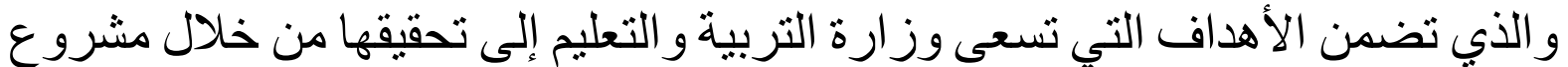
إدخال الحاسب في المرحلة المتوسطة ، وحددت آليات التنفيذ والتي منها محو أمية الحاسب لاى جميع العاملين والتلامبذ في المدارس التي يطبق فيها المشروع في في السنة الأولى ومن ثم في السنو ات التالية يتم تدريب المعلمين على استخدام الحاسب ولتبل وتطبيقاته

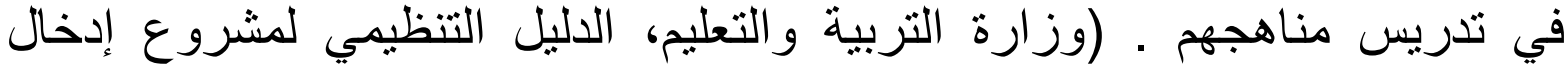
الحاسب، 1425 14هـ).

https://ijicet.journals.ekb.eg/ IJAI المجلة الدولية للأكاء الإصطناعى فى التعليم والتدريب 
هذه الآليات التي حددتها وزارة التربية و التعليم في الدليل الخاص بإدخال

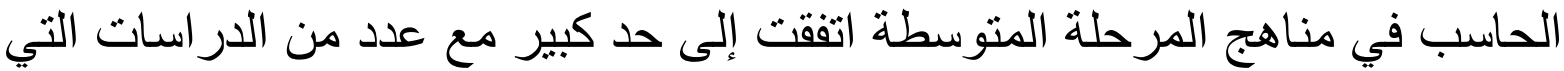

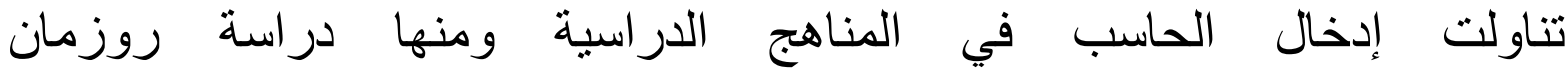

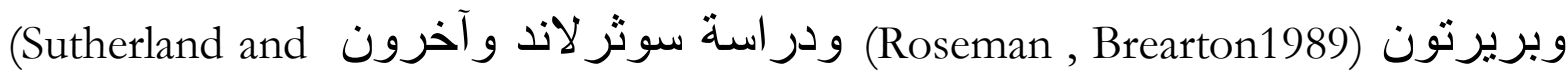
(Other 1991، و أيدت ذللك در اسة المنيع (1421هـ)، ودر اسة المناعي (1995م) .

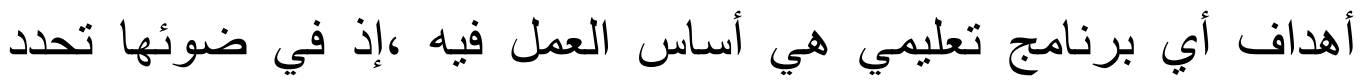

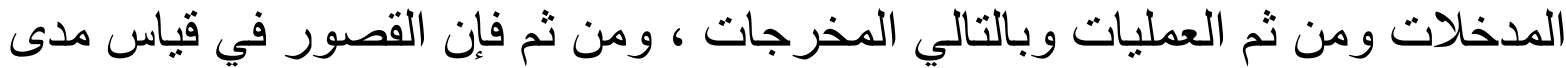

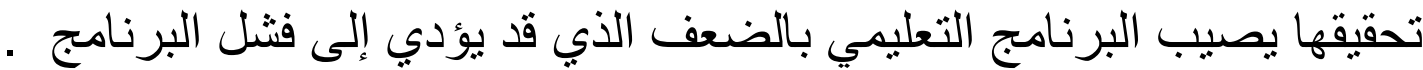
ويرى (عفيفي ،1980م) أن كثيراً من مشكلات النظم التعليمية تحدث نتيجة لغموض أهدافها وعدم قدرة العاملين على ترجمنها وتحقيقها. ويعد قياس مدى تحقيق الأهداف طريقة جيدة لتجويد الأعمال و التحقق من أدائها

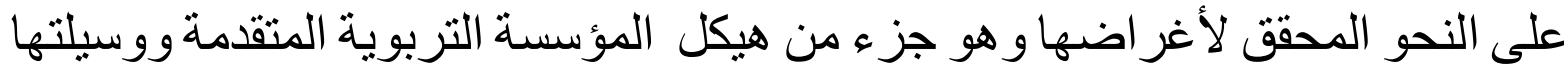

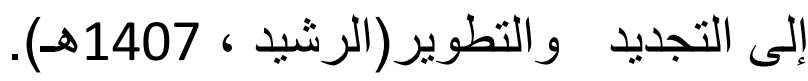

و هذا ما أكد عليه الباحثون في در اساتهم التي تناولت إدخال الحاسب في مناهج

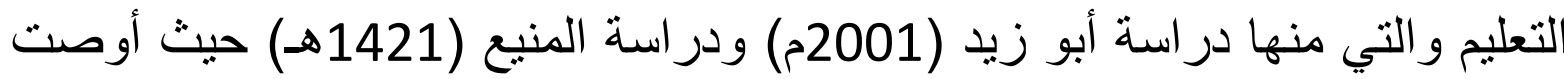

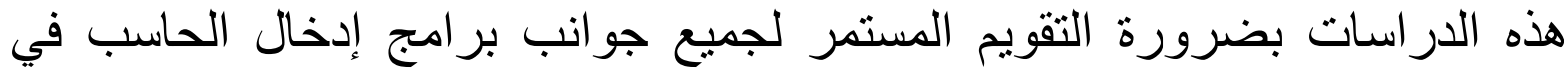
الهناهج التعليمية ومن تلك الجو انب جانب الأهداف حيث يثكل هذا لهن الجانب أهمية كبيرة

اطلع الباحث على توصيات اللقاء الأول للمشرفين التربويين العاملين

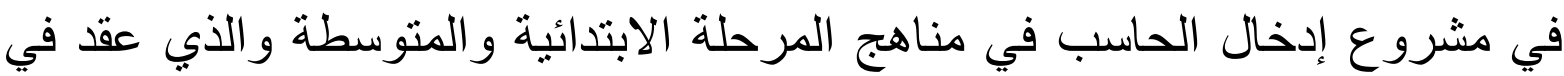

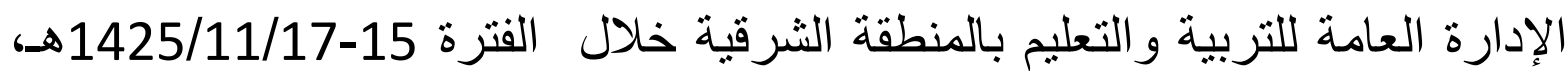

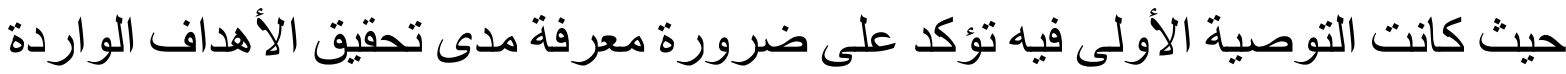

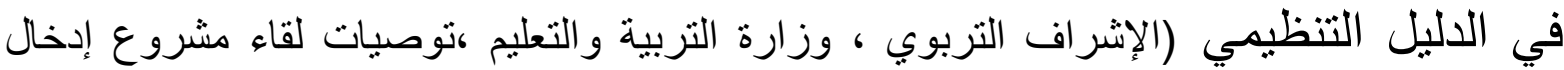
الحاسب في المرحلة الابتدائية والمتوسطة، 1425هـ).

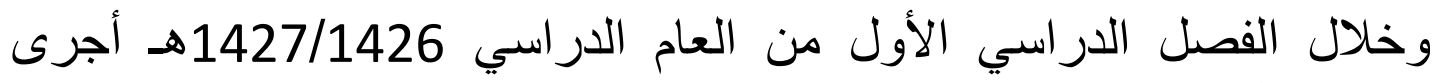

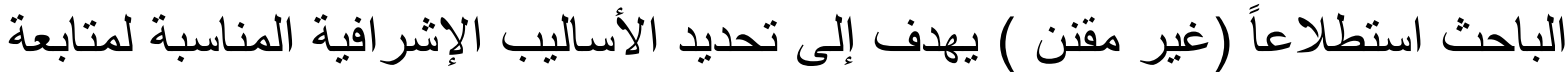

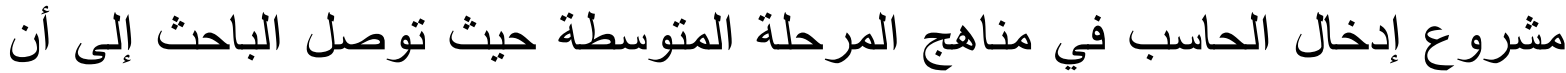


هناللك قصوراً في تحقيق الأهداف التي حددت في الاليل التظيمي لمشروع إدخال

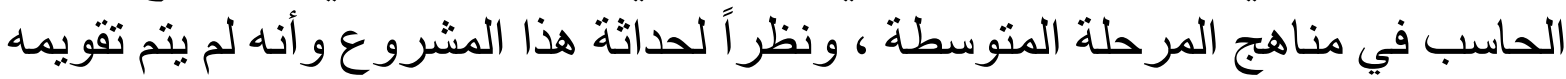

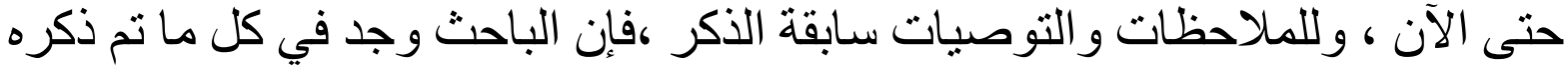
مشكلة تستحق البحث و التقصي و هي تتمثل في الحاجة إلى معرفة مدى تحقيق أهداف مشروع إدخال الحاسب في مناهج المرحلة المتوسطة 2. الهداف البحث

يسعى هذا البحث إلى تحقيق الأهداف التالية:

1- تعرف مدى تحقيق أهداف مشروع إدخال الحاسب في مناهج المرحلة المتوسطة التي حددها الدليل التنظيمي من وجهة نظر أفر اد العينة . 2- تعرف مدى ممارسة أفراد العينة لآليات مشروع إدخال الحاسب في مناهج

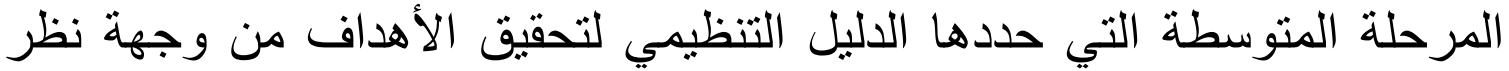
أفر اد العينة .

3- تعرف مدى توفر الإمكانات و التسهيلات المتو افرة لتحقيق أهداف مشروع إدخال الحاسب في مناهج المرحلة المتوسطة من وجهة نظر أفر اد العينة.

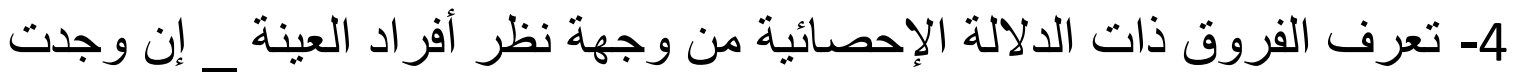

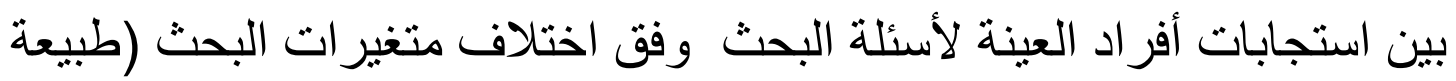
العمل -سنو ات الخبرة ،المستوى العلمي و المؤهل الأكاديمي).

ـ تعرف المعوقات التي تحول دون تحقيق أهداف مشروع إدخال الحاسب في مناهج المرحلة المتوسطة ( إن وجدت) من وجهة نظر أفراد العينة.

1. الطلاب : حيث تبرز أهمية الحاسب وتطبيقاته في البر امج التعليمية ودوره في

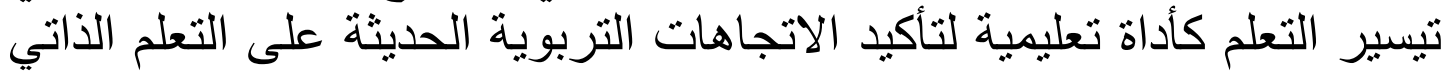
ومر اعاة الفروق الفردية بين المتعلمين ( الدبسي، ندئ 1999م). 
2. التطوير التربوي : حيث إن ما يسفر عنه البحث من نتائج سيكون بإذن الله عونا لمطوري المناهج الدراسية لتوظيف الحاسب كأداة تعليمية في الخطط العانية

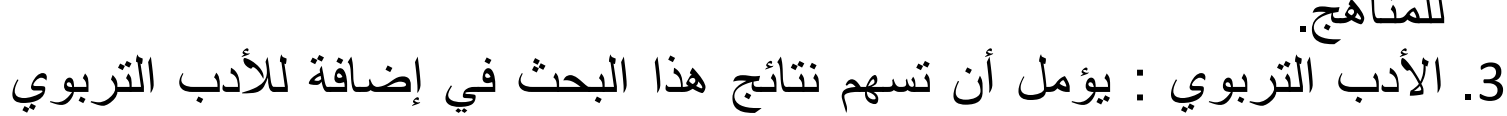

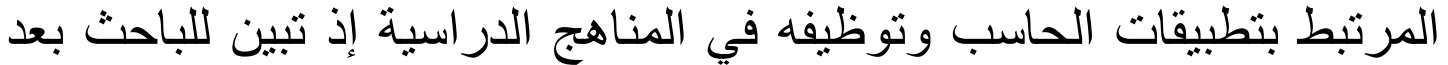

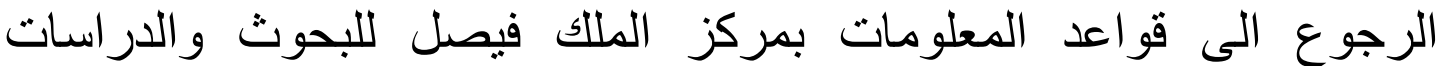

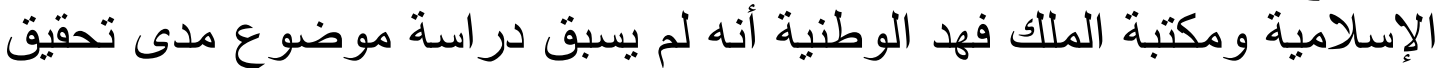

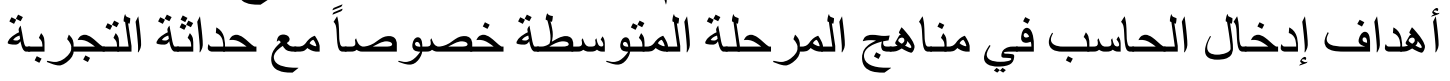
في المملكة العربية السعودية .

\section{3. أسئلة البحث :}

\section{يحاول هذا البحث الإجابة عن الأسئلة التالية:}

1- ما مدى تحقيق أهداف مشروع إدخال الحاسب في مناهج المرحلة المتوسطة من وجهة نظر أفراد العينة (مديرو المدارس فئرس ،المعلمون

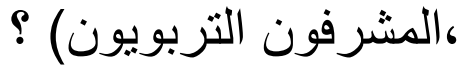

2- ما مدى ممارسة أفراد العينة (مديرو المدارس ،المعلمون ،المشرفون المبرن

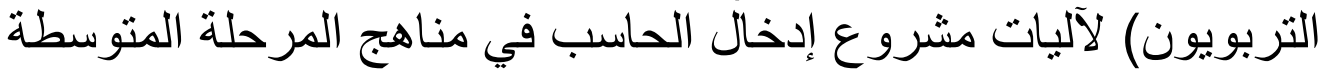
التي حددها الدليل التنظيمي لتحقيق الأهداف التباف

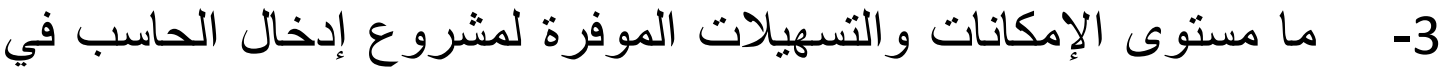

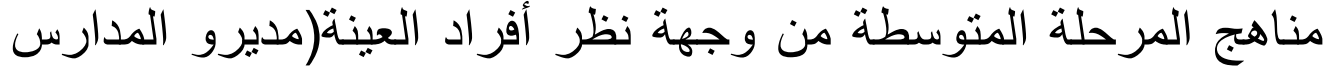

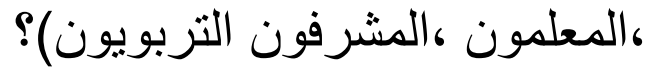

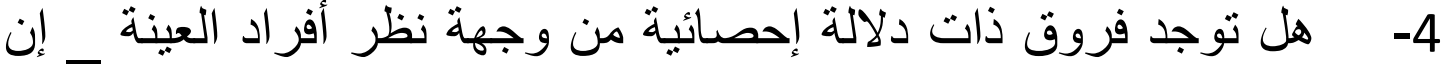

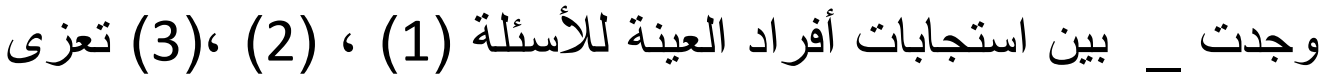

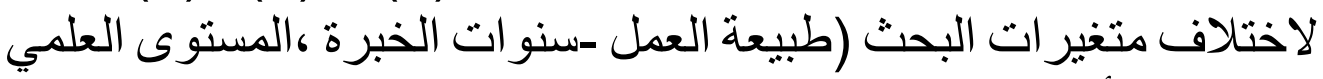

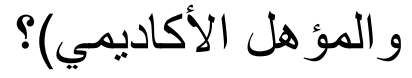

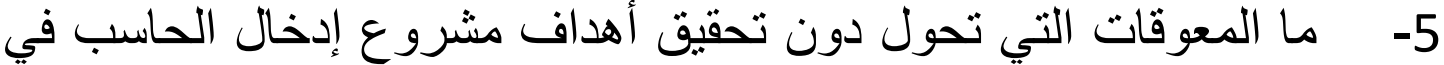

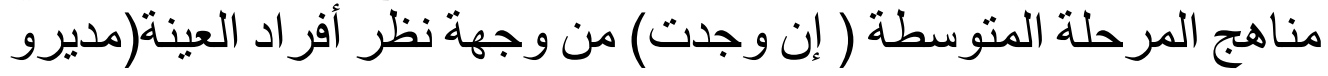
الددارس ،المعلمون ،المشرفون التربويون)؟

\section{4. - صطلحات البحث :}


يعرف الهدف في الاصطلاح التربوي بأنه "أي تغير ير اد إحداثه في سلوك كوائ

المتعلمين كنتيجة لعملية التعلم "( هندي و عليان ،1999م).

وعرف الثنافعي وزملاؤه الأهداف التربوية بأنها " ما تسعى التربية إلى تحقيقها

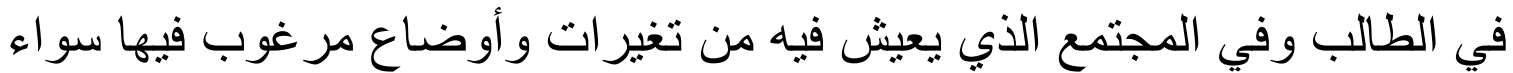

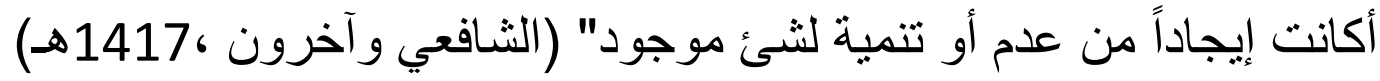

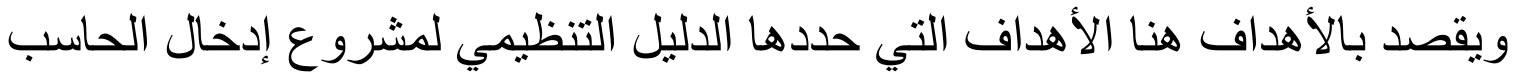

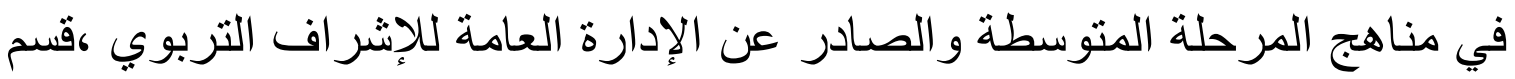
الحاسب، وزارة التربية والتعليم وكانت على النحو التالي: 1. محو أمبة الحاسب من خلال تهيئة المعلمين والطلاب لاستخدام الحاسب في التعليم في السنوات القادمة.

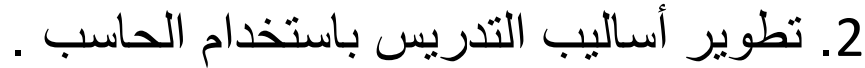
3. إعداد بيئة تعليمية تفاعلية داخل المدرسة.

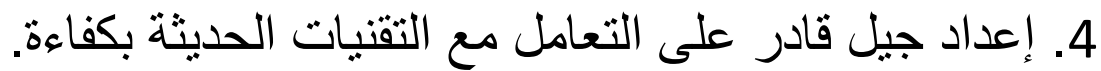
5. إتاحة الفرصة للطالب للتعلم بطرق و أساليب متعددة التهات

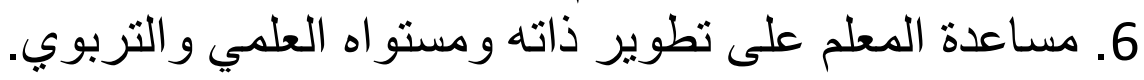

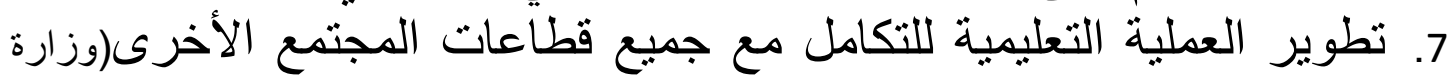
7. التربية و التعليم، الدليل التنظيمي لمشروع إدخال الحاسب ،1425هـ).

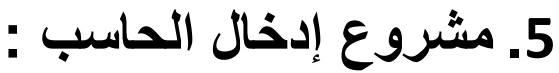

تضمن البدء بتدريس الحاسب عبر مقررات دراسية تعد لذلك ويكون

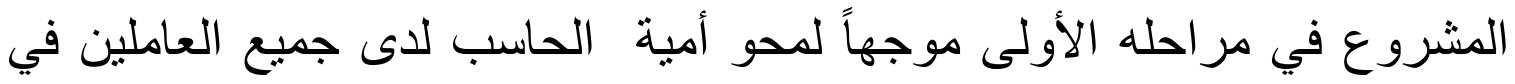

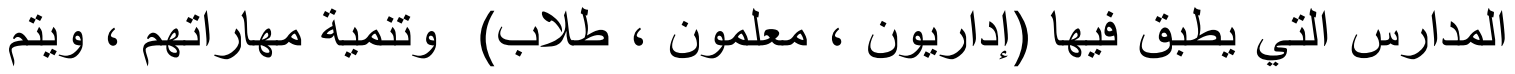

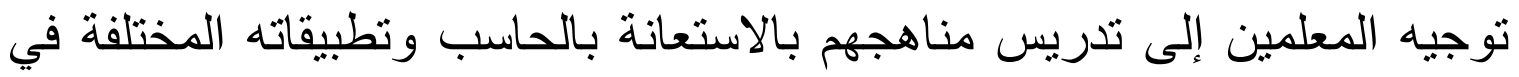

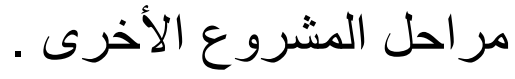

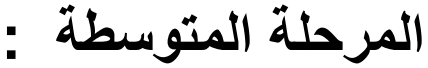

https://iiicet.journals.ekb.eg/_ IJAI المجلة الدولية للأكاء الإصطناعى فى التطليم والتصريب 
هي المرحلة التعليمية الثانية في سلم التعليم النظامي العام بالمملكة

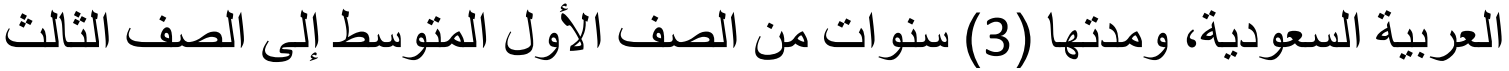

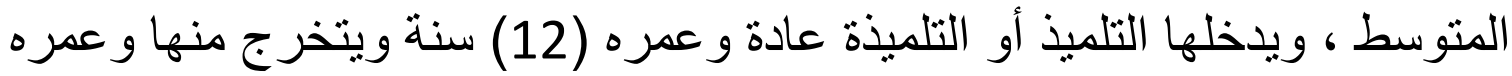

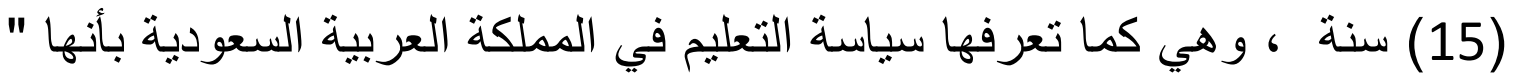

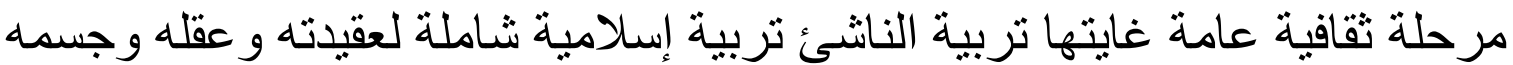

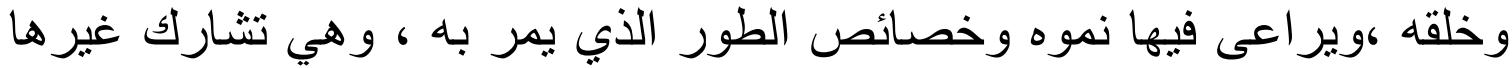
في تحقيق الأهداف العامة من التعليم " .( الحقيل ، 1415هـ) .

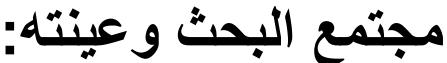

يتكون مجتمع البحث و عينته مما يلي :

1. مديرو المدارس المتوسطة الحكومية التي طبق فيها مشروع إدخال الحاسب في مناهج المرحلة المنوسطة بمدينة الرياض في العينة فئنة العام (1426-

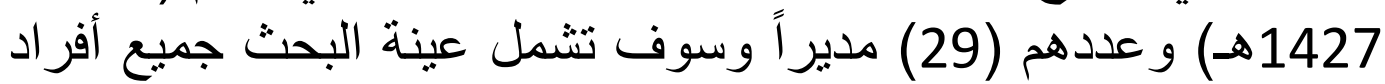

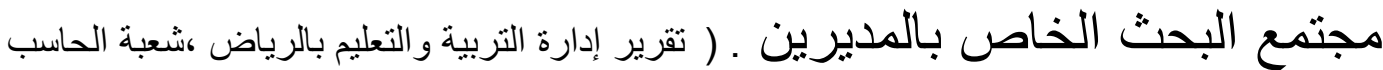
(1426،

2. المشرفون التربويون الذين كلفوا بمتابعة المشروع بمدينة الرياض في في العي في

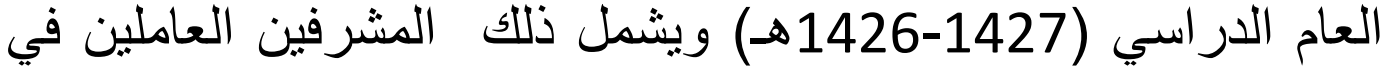
جهاز الوزارة قسم الحاسب والمشرفين التابعين للإدارة العامة للتربئية

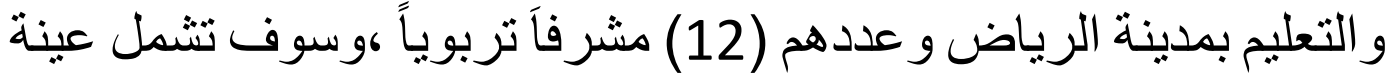
البحث جميع أفر اد مجتمع البحث الخاص باصنية بالمشرفين ـ ( تقرير إدارة الثربية

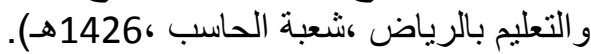

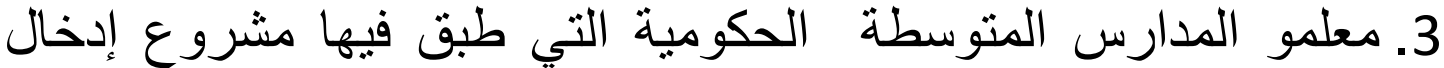

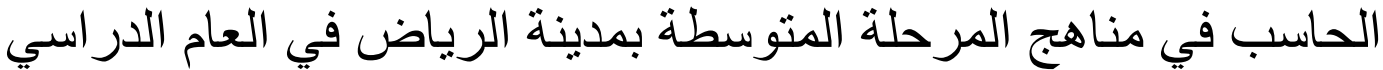

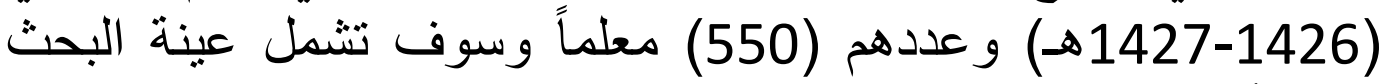

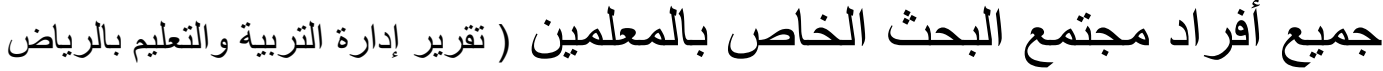

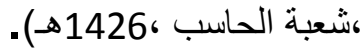

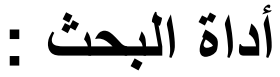

https://ijicet.journals.ekb.eg/ IJAI المجلة الدولية للأكاء الإصطناعى فى التعليم والتدريب 


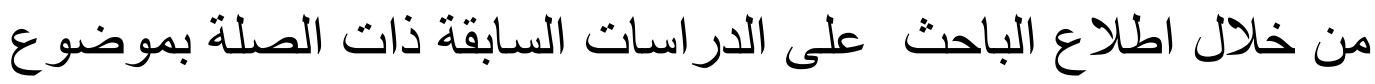
البحث،واستشارة الباحث لعدد من المختصين في مجال البحث ، قام البثات الباحث

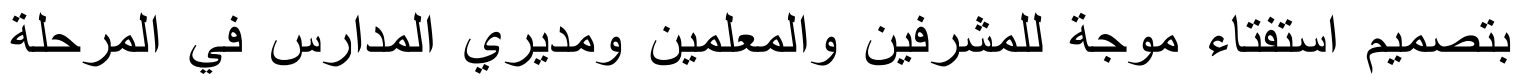
المتوسطة الحكومية للبنين بمحافظة الرياض ،وذلة للك لمعرفة مدى تحقيق أهداف

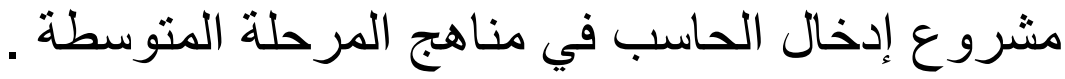
ومن خلال الاستفتاء تم جمع بيانات البحث اللازمة للإجابة عن أسئلة البحث

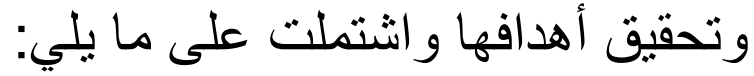

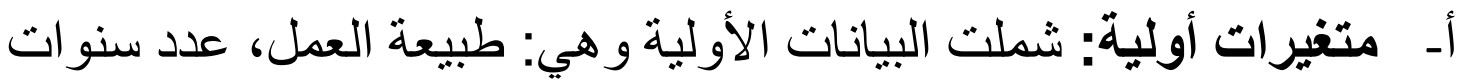

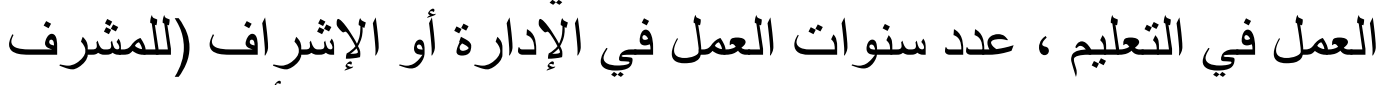

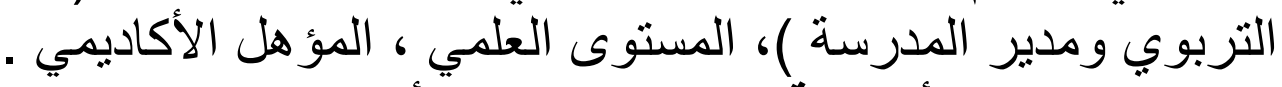

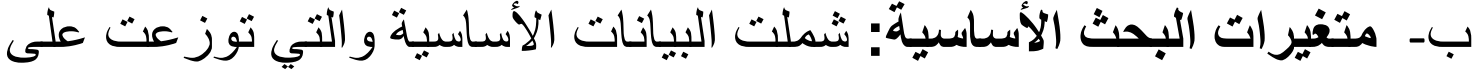

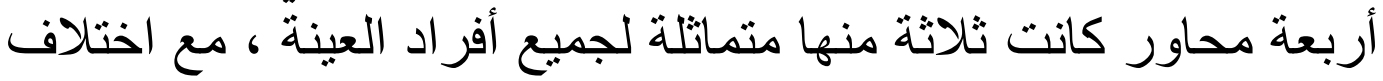

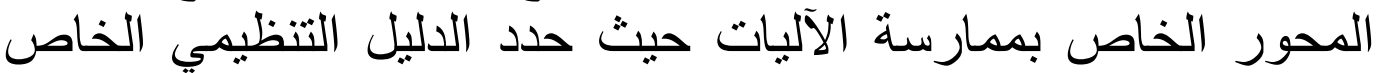

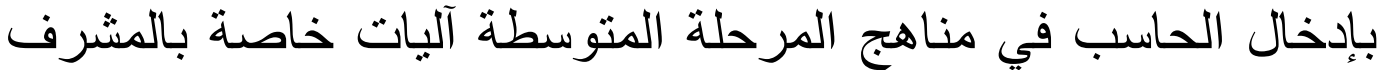
التربوي ، وآليات خاصة بمدير المدرسة والئ المعلم وكانت محاور الاستفتاء

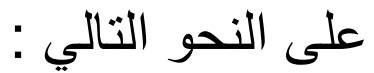

المحور الأول: أهداف مشروع إدخال الحاسب في مناهج المرحلة المتوسطة. المحور الثاني: مدى ممارسة أفراد العينة لآليات المشروع .

المحور الثالث: الإمكانات والتسهيلات المتوافرة لتحقيق أهداف المشروع . المحور الرابع: المعوقات التي تحول دون تحقيق الأهداف .

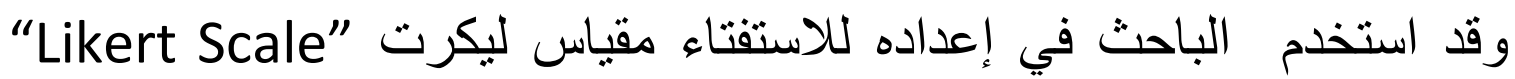

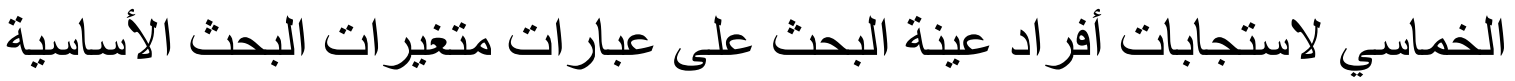

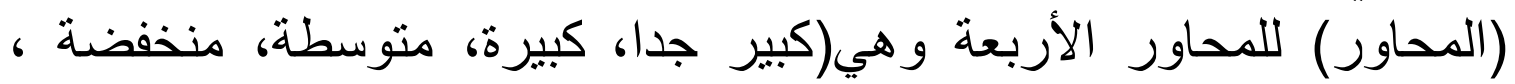


معدومة)، حيث يعبر الرقم (5) عن أعلى درجة وهي (كبير جدا)، بينما يعبر

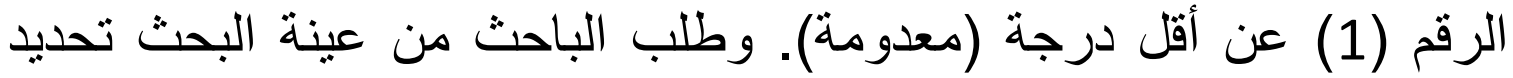

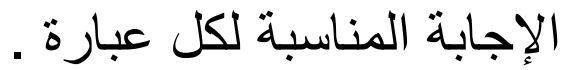

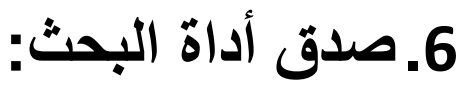

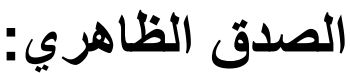

قام الباحث بعرض أداة البحث وهو الاستفتاء في صورته الأولية على في مجموعة من المحكمين المختصين في المناهج والحاسب واستخداماته في الاستي

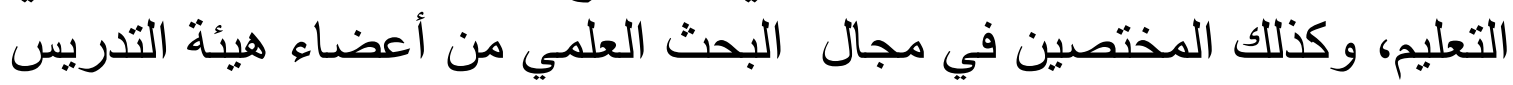

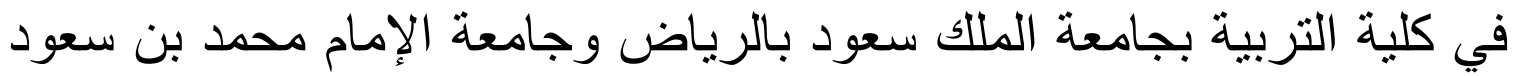
الإسلامية ، و الجامعة الأردنية بعمان وكذا عدد من الرية المشرفين الإنين التربويين المختصين في مجال الحاسب الآلي في وزارة التربية ولئية والتعليم.

حيث طلب منهم الباحث إبداء الر أي حول مدى وضوح العبارات ومناسبتها

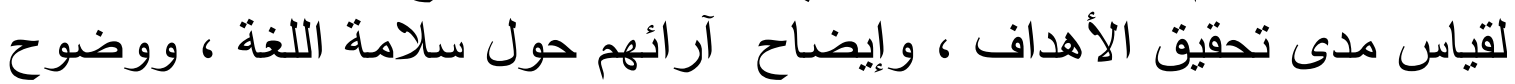

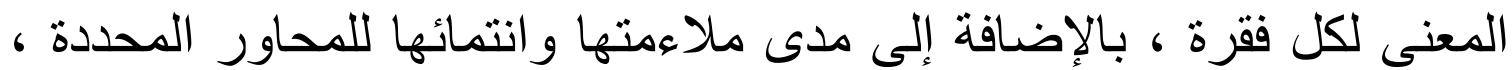

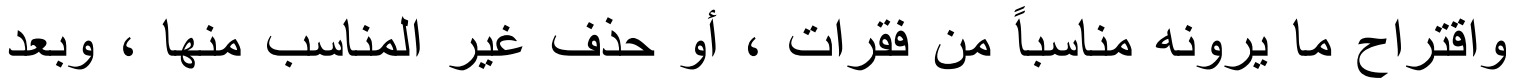

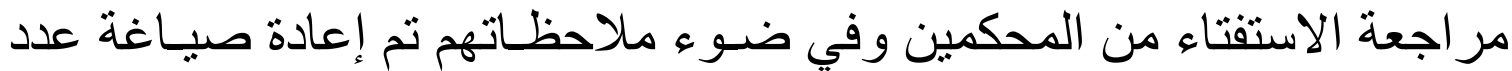
من فقر اتها ، و استبـدال مجمو عـة أخرى من فقر اتها بفقر ات جديدة

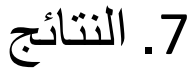

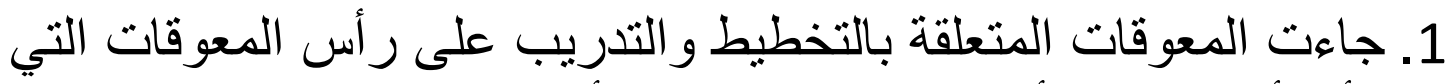

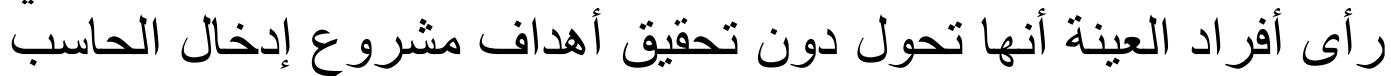

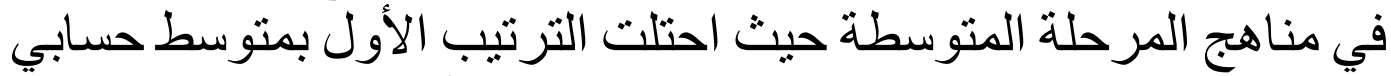

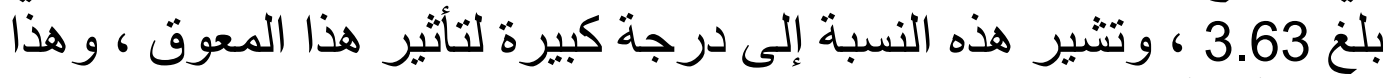

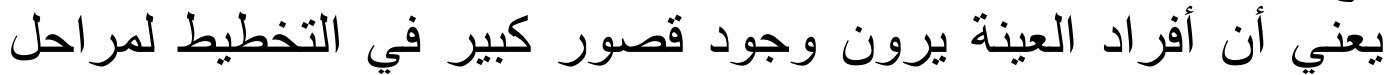
المشروع وكذللك الدورات التدريبية ،وتتفق هذه النتيجة مع (ابوزيد فيطي ليراحل 


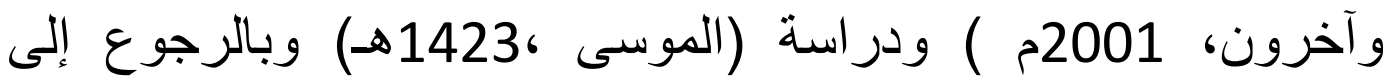
تفاصيل الصعوبات في الجدول (22-5) يلاحظ أن العبارة التي تتضدن الترن

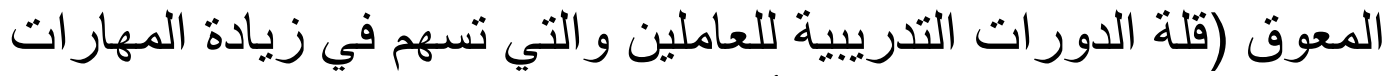

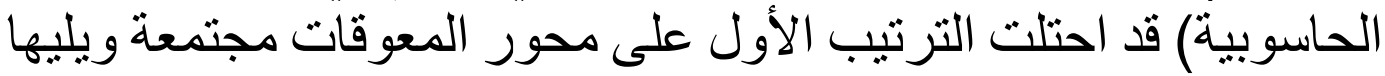

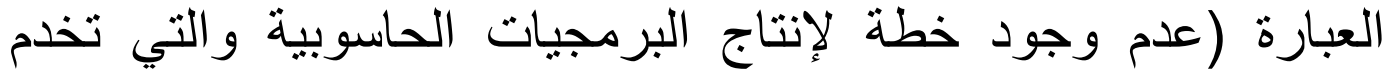

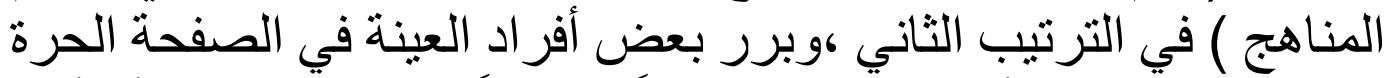

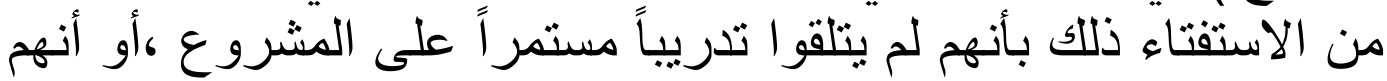

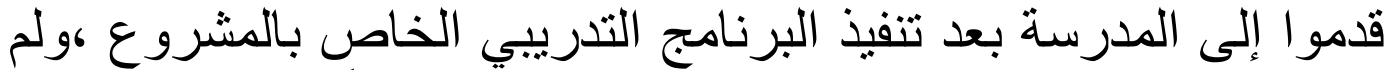

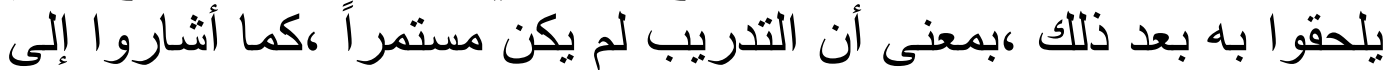

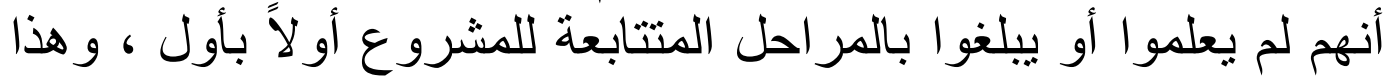

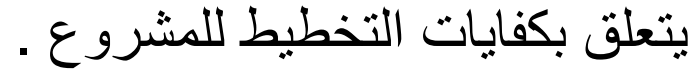

2. مجموعة المعوقات المتعلقة بالبرمجيات جاءت في الترنيب الثاني

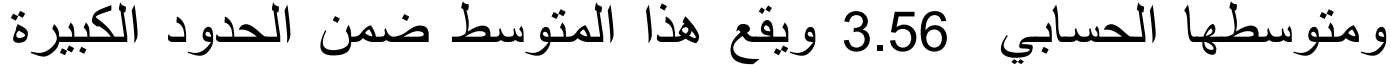

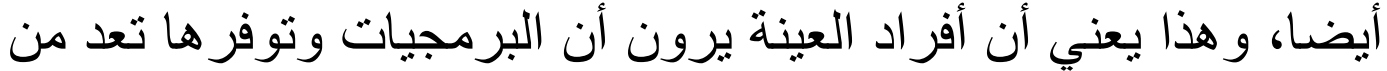

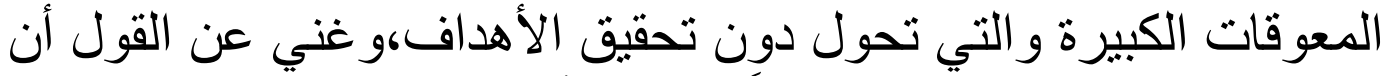

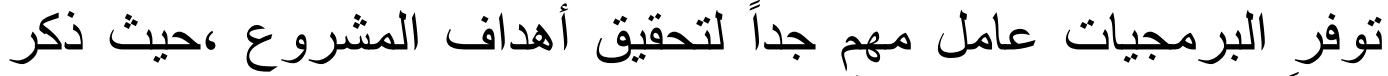

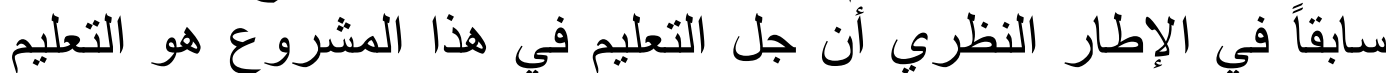

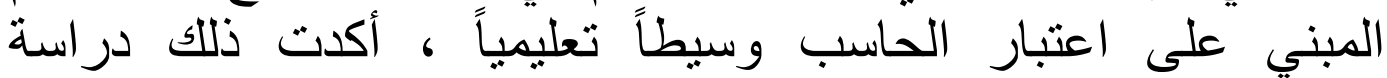

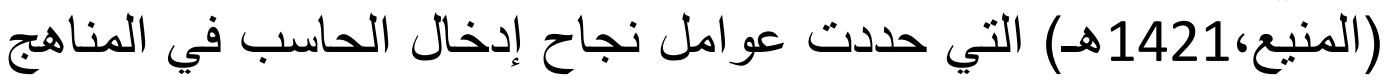

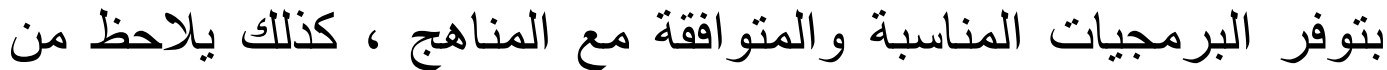

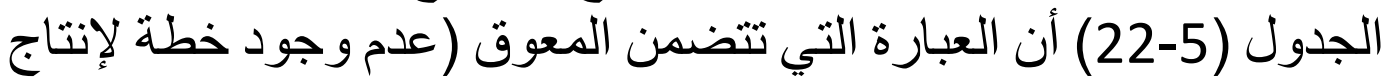

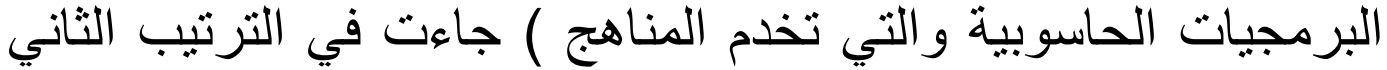

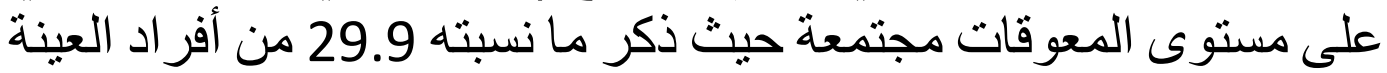

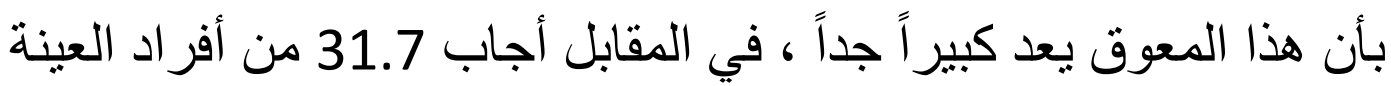

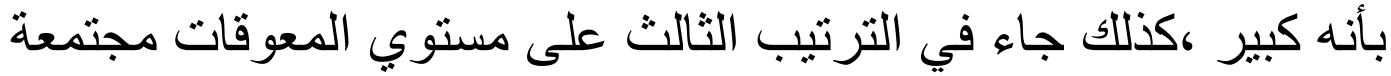

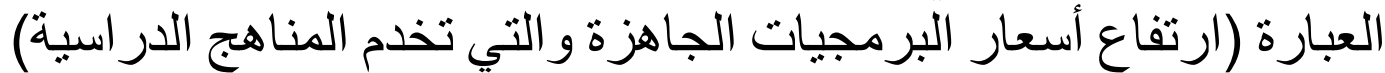

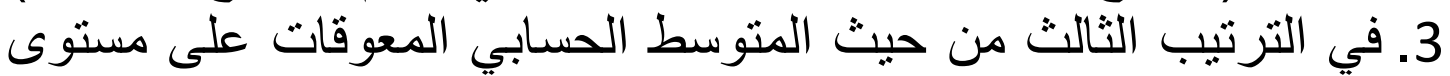
المناهج حيث احتلت العبارة (قصور بناء المناهج الدئ الدراسية بأسلوب 


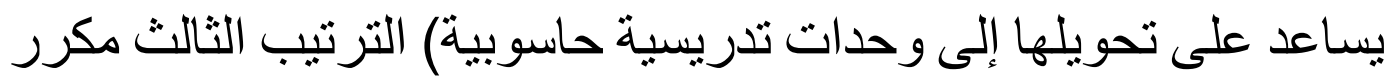

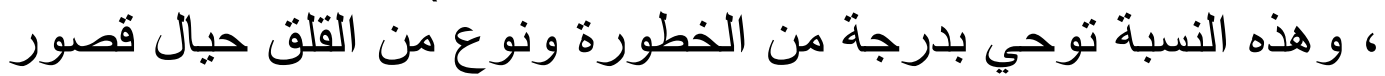

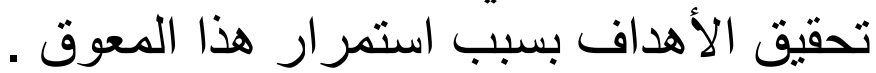

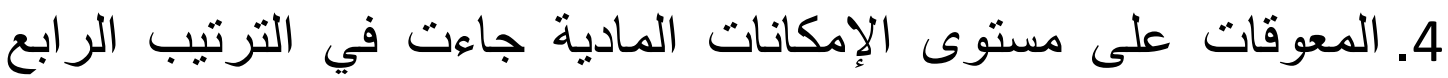

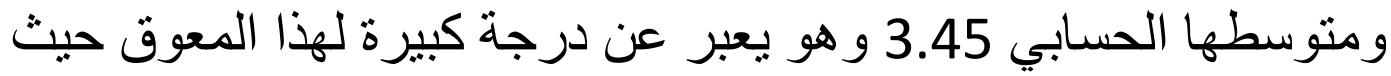

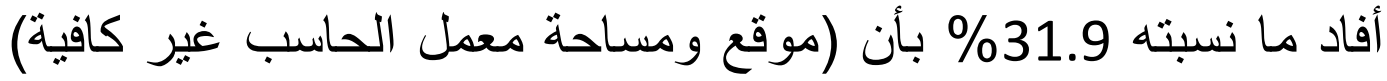

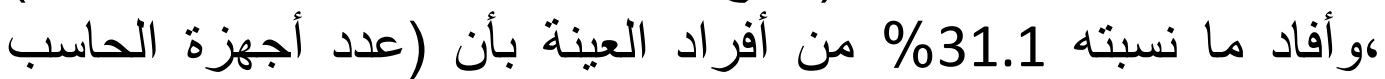

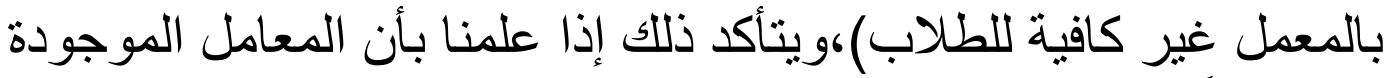

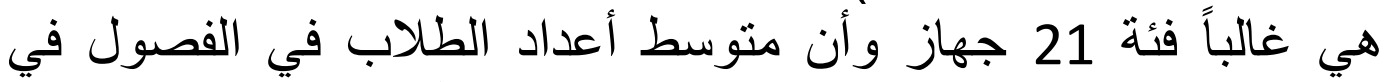
المدارس التي زارها الباحث لا يقل عن 25 طالباً .

5. في الترتيب الخامس والأخير من حيث المتوسط جاءت المعوقات على المئ

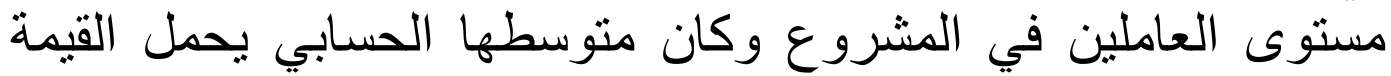

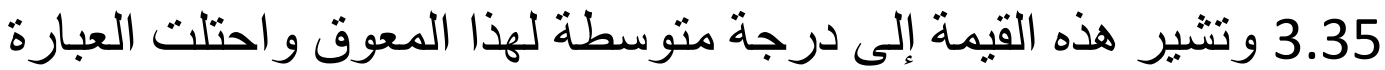
(القصور في تعريف المشرفين مديري المدارس و والمعلمين ودين ومحضري

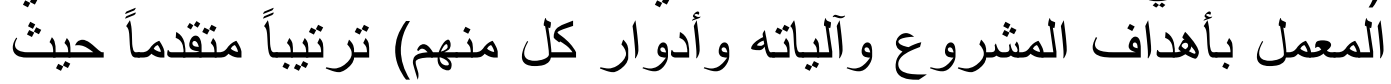

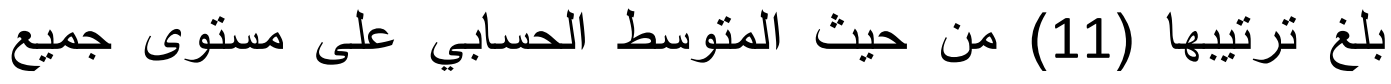

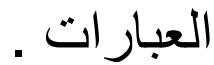

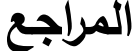

أبن المنظور ، محمد بن مكرم (1413هـ) .لسان العرب ـ بيروت : دار إحياء

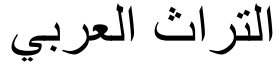

ابوزيد ،عمار ،آخرون .(2001م)، توظيف الحاسب الآلي والمعلوماتية في

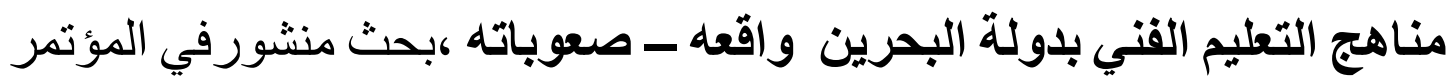

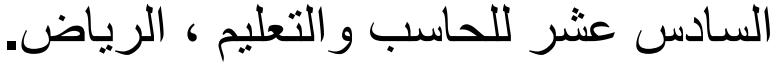

https://ijicet.journals.ekb.eg/ IJAI المجلة الدولية للأكاء الإصطناعى فى التطليم والتصريب 
بدر،بثينه.(1422هـ) ـ أثر استخلام الحاسب في التدريب على حل المشكلات

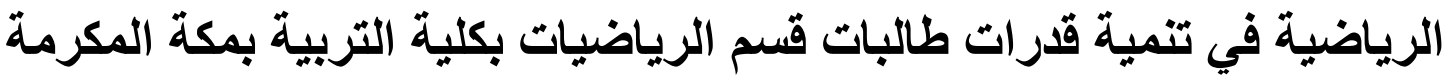

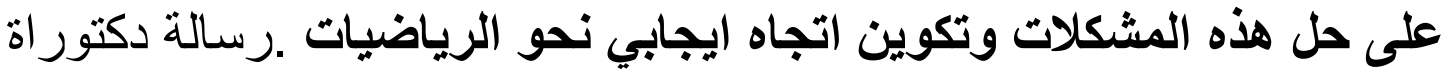

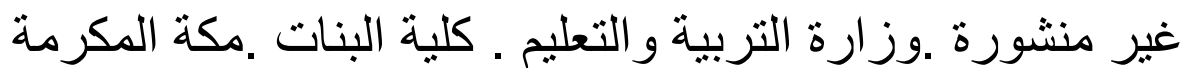

بلوم ،بنجامين وآخرون (1405هـ) .نظام تصنيف الأهداف التربوية .جدة : دار

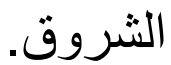

بن طالب ،عبدالعزيز (1420هـ). مدى تحقيق أهداف مقررات الثقافة الإسلامية

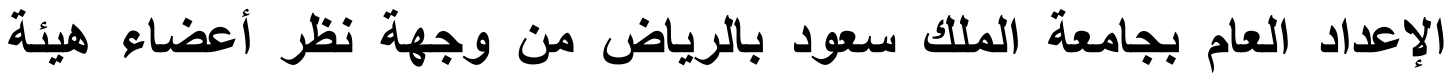
التدريس والطلاب. رسالة ماجستير غير منشورة ، كلية التربية ، جامعة الملك الكاءئ

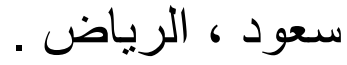

تايلور ،ر الف (ترجمة كاظم ،و آخرون 1982م).أساسيات المناهج ـالقاهرة :دار النهضة

التقرير السنوي عن تعليم البنين والبنات في المملكة العربية السعوديـة::

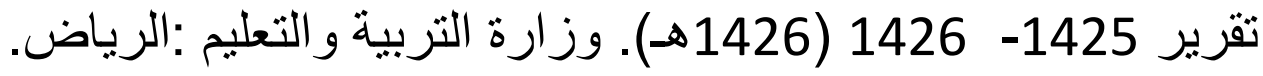

تقرير تعليم الرياض حول مشروع إدخـال الحاسب في مناهج المرحلة

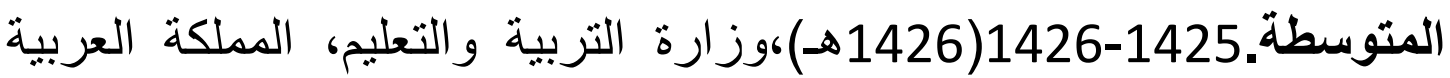

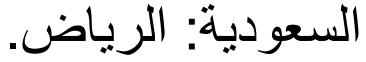


الحازمي ،مطلق. (1416هـ). تقويم البرمجيات الرياضية المستخدمة على العى (55) الحاسب الآلي .رسالة الخليج ـ العدد (55).

حسن، امتثال محمد.(1997م). مبادئ الإحصاء. الإسكندرية.مطابع كلية التجارة.جامعة الإسكندرية.

الحقيل ،سليمان .(1415) .نظام وسياسة التعليم في الملكة العربية السعودية.الرياض: مكتبة الملك فهد الوطنية .

الخباز، مكي (1415هـ). مشروع إذخال الحاسب في التعليم بدولة الكويت. وقائع ندوة الحاسب في جامعات دول الخليج العربي. مثرع الخال الحبي في

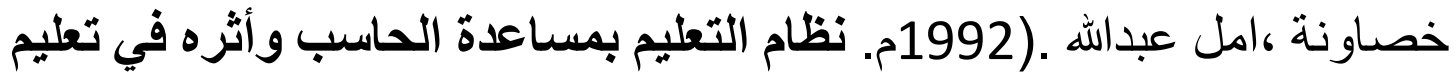

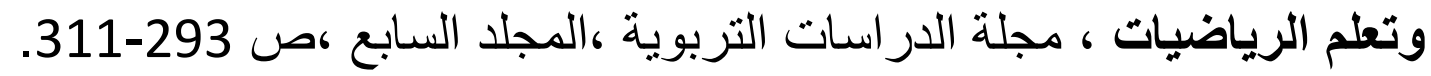

الخليفة ، حسن جعفر ـ ( 1424هـ ) ـ المنهج المدرسي المعاصر ـ الرياض :

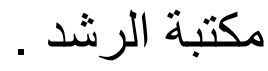

الدبسي ، أحمد عصسام ( 1999م ). دور الحاسب في تطوير التربية البيئية وفق المقائ

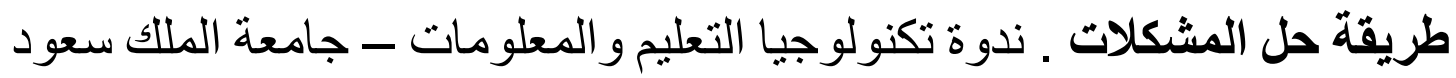

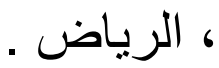


الر اثند ، فارس بن إبر اهيم ( 1424هـ ) التعليم الإكتروني واقع وطموح. ورقة عمل مقدمة لندوة التعليم الإلكتروني) ـ مدارس الملك فيصل: الرياض.

الرشيد ،محمد أحمد .(1407هـ)،ملف التقويم الذاتي ، رسـالة الظليج العربي .

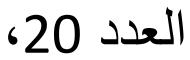

زهران ، حامد عبدالسلام .( 2003م ). علم نفس النمو : الطفولة والمراهقة

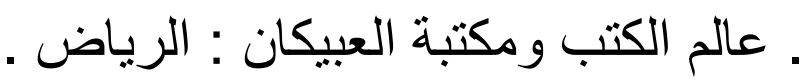

الز هر اني ،سميرة. (1426هـ) ـاستخلام الحاسب الآلي في تعليم القرآن

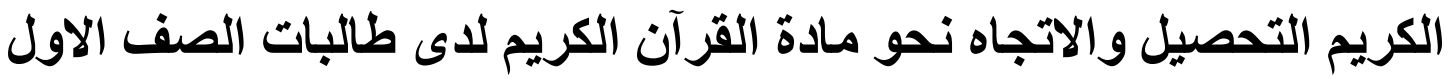

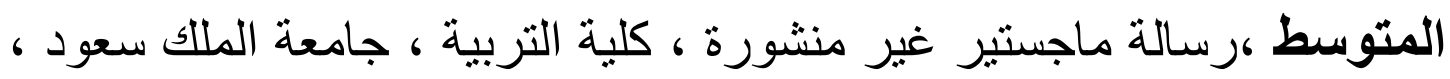

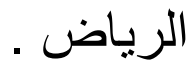

سرحان ، الدمرداش عبدالمجيد (1401هـ). المناهج المعاصرة . الكويت : مكتبة الفلاح

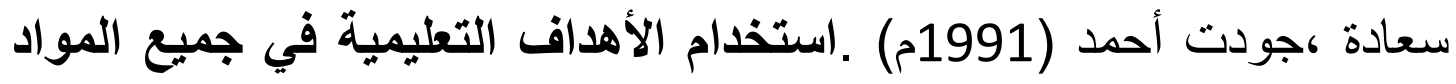

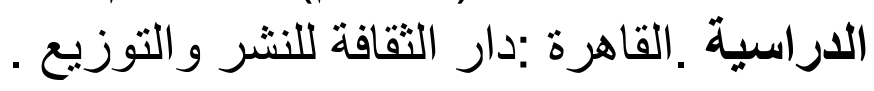

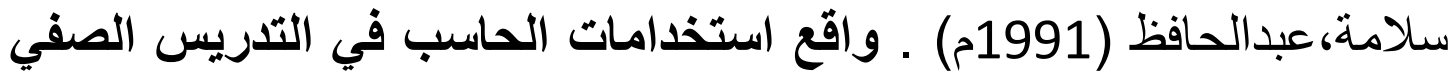

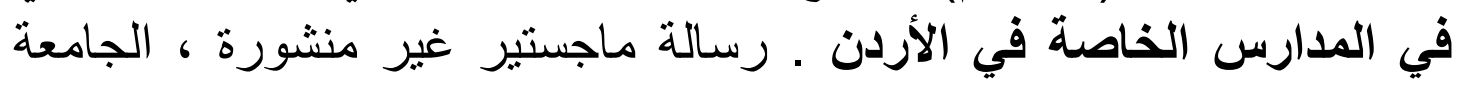
الأردنية ، عمان .السنة (7). 
السيد ، محمد علي .(1999م) ـ الوسائل التعليمية وتكنولوجيا التعليم ، دار

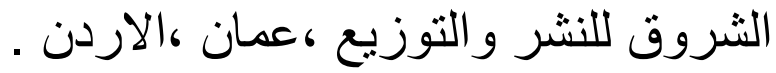

الثناعر ، عبدالرحمن و الصالح، بدر ( 2000م ) تقرير مبائي حول دراسة

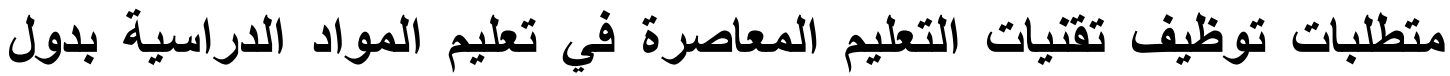

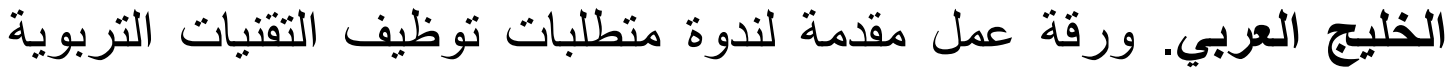

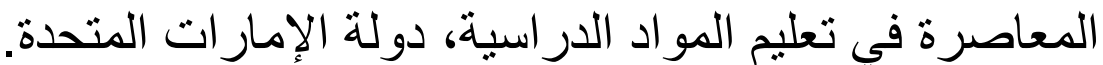

الثنافعي ،إبر اهيم، آخرون. (1417هـ) ـالمنهج المدرسي من منظور جديد .

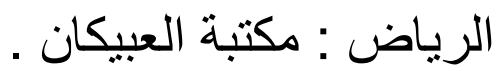

الثويعر ، مشاعل عبدالرحمن (1419هـ ). اتجاهات المشرفات والمديرات

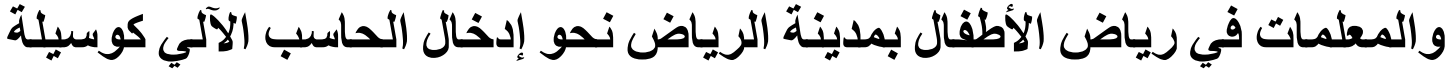

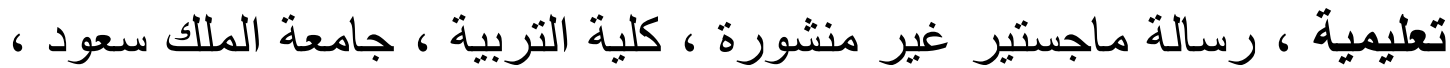

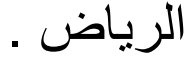

الصالح ، بدر (1423هـ ). التقتية ومدرسة المستقبل. بحث مقدم في ندوة

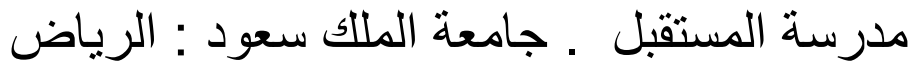

الصقر ،عبدالعزيز ـ ( 1421هـ). تقويم برامج الحاسب التعليمية المستمدة من

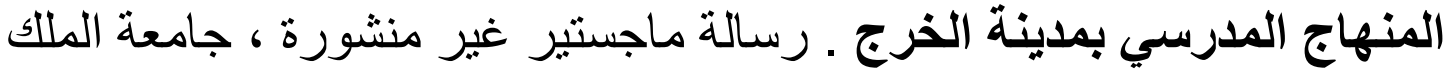

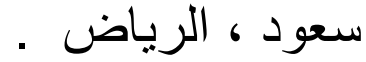


الضحيان، ماهر.(1423هـ).مدى تحقيق أهداف مقررات الإعداد التربوي

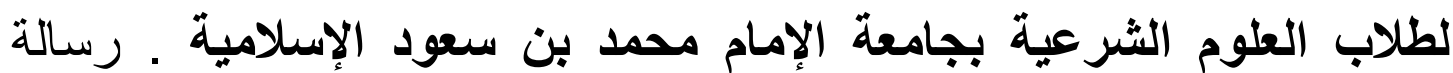

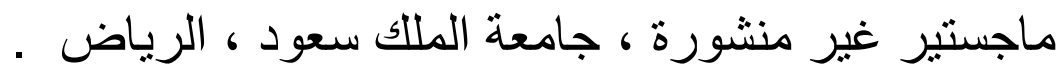

طلافحة ، عبدالحميد حسن (1998م) ـ تقويم برمجيات الحاسب المستخدمة في الصفوف الثلاثة الأخيرة من وجهة نظر معلمي الحاسب الآلي واتجاهاتهم

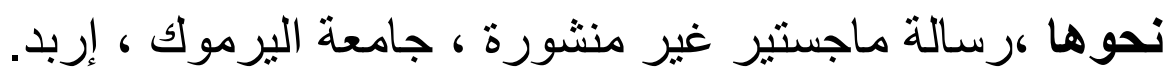

العبدالكريم ،إيمان عمر ( 1419هـ). أثر تدريس الكيمياء بالحاسب الآلي على الكي

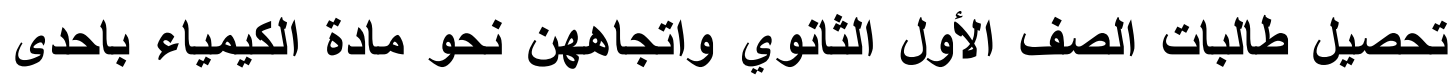
المدارس في مدينة الرياض . رسالة ماجستير غير منشورة ، جامعة الملك

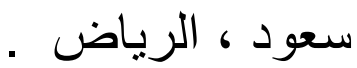

عبيدات ، ذذوقان و عداس،عبدالرحمن،و عبدالحق، كايد . (2003م)،البحث العلمي مفهومه وأدواته وأساليبه ، الرياض كونيل ، مكتبة العبيكان.

عريشي،علي .(1426هـ).مدى تحقيق برامج التوعية الإسلامية أهدافها في

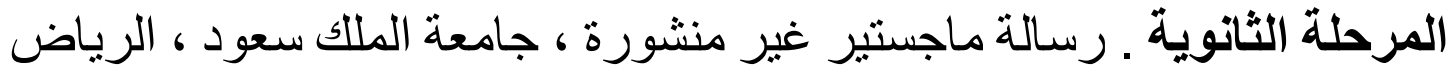

العساف، صالح (1416هـ). المدخل إلى البحث في العلوم السلوكية. الرياض: شركة العبيكان للطباعة و النشر. 


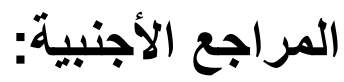

Backer, H. J (1984)" Computer in School today" Some Basic Consideration". Amarican Journal of Education.1.

Ely, P. (1993) Computer in school in the united States of Amarica. Educational Technology, September.

Fong, H. (1989): “ Models for the Integration of computing into Mathematics Curriclum" Computers in Education.3.

Pelgrum, w. \& Plomp: (1991) The Use of Computer In Education World-Wide. Oxford; Programon Press.

Rosman,j and Brearton,M (1989).Computer to enhance Science Education:An inservice designed to faster Classroom Implementation, The Annual Meeting Of the National Association for Research in Science Teaching at san Francisco, California.

Shayo, C . Olfman , 1. Guthrie, R .(2000). "Integration of IT into the School Curricula : Perception of Kindergarden to

https://ijicet.journals.ekb.eg/ IJAI المجلة الدولية للأكاء الإصطناعى فى التعليم والتدريب 
highschool (K-12) Teacher,"SIGCPR 2000: Evanston Illionis USA.

Sutherland ,R .Hoyles, C and Noss,R .(1991). The microworlds Course: Description and Evaluation. London, Institute of Education, University of London.

Taylor, R. (1980): The Computer in the School: Tutor, Toll, Tutee. New York: Teacher College Press. 